Article

\title{
Pioglitazone-Mediated Peroxisome Proliferator-Activated Receptor $\gamma$ Activation Aggravates Murine Immune-Mediated Hepatitis
}

\author{
Rike Schulte ${ }^{1}$, Dirk Wohlleber ${ }^{1,2}$, , Ludmilla Unrau ${ }^{3}$, Bernd Geers ${ }^{3}$, Christina Metzger ${ }^{1}$, \\ Annette Erhardt ${ }^{3}$, Gisa Tiegs ${ }^{3}$, Nico van Rooijen ${ }^{4}$, Lukas C. Heukamp ${ }^{5}$, Luisa Klotz ${ }^{1,6}$, \\ Percy A. Knolle ${ }^{1,2}$ and Linda Diehl ${ }^{1,3, *}$ \\ 1 Institute for Molecular Medicine and Experimental Immunology, University Hospital Bonn, Bonn, Germany; \\ rike.schulte@gmail.com (R.S.); ga59siw@mytum.de (D.W.); c_metzger@gmx.net (C.M.); \\ luisa.klotz@ukmuenster.de (L.K.); percy.knolle@tum.de (P.A.K.) \\ 2 Institute of Molecular Immunology and Experimental Oncology, Technical University Munich, \\ 81675 Munich, Germany \\ 3 Institute of Experimental Immunology and Hepatology, University Medical Center Hamburg-Eppendorf, \\ 20246 Hamburg, Germany; l.unrau@uke.de (L.U.); b.geers@uke.de (B.G); \\ annette.erhardt.ae@googlemail.com (A.E.); g.tiegs@uke.de (G.T.) \\ 4 Department of Molecular Cell Biology, VU University Medical Center, 1081 HV Amsterdam, The \\ Netherlands; nvanrooijen@clodronateliposomes.org \\ 5 Institute for Hematopathology Hamburg, 22547 Hamburg, Germany; heukamp@hp-hamburg.de \\ 6 Department of Neurology, University Hospital Münster, 48149 Münster, Germany \\ * Correspondence: li.diehl@uke.de
}

Received: 3 March 2020; Accepted: 3 April 2020; Published: 5 April 2020

\begin{abstract}
The nuclear receptor peroxisome proliferator-activated receptor gamma (PPAR $\gamma$ ) regulates target gene expression upon ligand binding. Apart from its effects on metabolism, PPAR $\gamma$ activity can inhibit the production of pro-inflammatory cytokines by several immune cells, including dendritic cells and macrophages. In chronic inflammatory disease models, PPAR $\gamma$ activation delays the onset and ameliorates disease severity. Here, we investigated the effect of PPAR $\gamma$ activation by the agonist Pioglitazone on the function of hepatic immune cells and its effect in a murine model of immune-mediated hepatitis. Cytokine production by both liver sinusoidal endothelial cells (IL-6) and in T cells ex vivo (IFN $\gamma$ ) was decreased in cells from Pioglitazone-treated mice. However, $\operatorname{PPAR} \gamma$ activation did not decrease pro-inflammatory tumor necrosis factor alpha TNF $\alpha$ production by Kupffer cells after Toll-like receptor (TLR) stimulation ex vivo. Most interestingly, although $\operatorname{PPAR} \gamma$ activation was shown to ameliorate chronic inflammatory diseases, it did not improve hepatic injury in a model of immune-mediated hepatitis. In contrast, Pioglitazone-induced PPAR $\gamma$ activation exacerbated D-galactosamine (GalN)/lipopolysaccharide (LPS) hepatitis associated with an increased production of TNF $\alpha$ by Kupffer cells and increased sensitivity of hepatocytes towards TNF $\alpha$ after in vivo Pioglitazone administration. These results unravel liver-specific effects of Pioglitazone that fail to attenuate liver inflammation but rather exacerbate liver injury in an experimental hepatitis model.
\end{abstract}

Keywords: TNF $\alpha$; Kupffer cell; PPAR $\gamma$, LPS; inflammation; Pioglitazone

\section{Introduction}

The transcription factor nuclear receptor peroxisome proliferator-activated receptor gamma $(\operatorname{PPAR} \gamma)$ has been shown to mediate anti-inflammatory effects on several immune cell types $[1,2]$. PPAR $\gamma$ heterodimerizes with the retinoid $X$ receptor upon ligand binding and then binds to PPAR 
response elements in the promoter region of target genes. Additionally, PPAR $\gamma$ negatively affects pro-inflammatory cell signaling, either via competition for co-activators or via transrepression through physical interaction with pro-inflammatory transcription factors, in particular NF-kB [2,3]. PPAR $\gamma$ agonists can be activated by endogenous ligands, such as polyunsaturated fatty acids and prostanoids like the prostaglandin D2 (PG- $\mathrm{D}_{2}$ ) metabolite 15-deoxy-D PG-J [4]. Additionally, several synthetic ligands exist, such as the anti-diabetic thiazolidinediones, e.g., Pioglitazone and Rosiglitazone, which can be used for the correction of metabolic disturbances in type II diabetes [5].

Various cell types of the immune system are affected in their function after PPAR $\gamma$ activation. In dendritic cells (DC), for instance, it prevents pro-inflammatory cytokine production and maturation, which can impede DC priming of CD4 T cells [6], and it affects DC migration and adhesion [7]. Also, in peripheral blood monocytes and peritoneal macrophages, PPAR $\gamma$ can downregulate the production of pro-inflammatory cytokines, like interleukin (IL) $1 \beta$, IL- 6 and TNF $\alpha$, and additionally affects the uptake and destruction of pathogens [8]. In T cells, PPAR $\gamma$ activation results in reduced proliferation and IL-2 production [4]. Furthermore, we could show that PPAR $\gamma$ activation interferes with retinoic acid receptor-related orphan receptor (ROR) $\gamma t$ transcription and thus, Th17 differentiation [9].

Liver disease is a major cause of morbidity and mortality worldwide. Both chronic and acute hepatitis can cause liver injury, which can lead to the development of liver cirrhosis and cancer. Hepatitis is largely mediated by immune effector mechanisms. PPAR $\gamma$ activation can have beneficial effects on disease onset and severity in various inflammatory disease models in the central nervous system, the gastrointestinal tract and the skin [9-11]. Thus, different hepatic immune cells that are implicated in the development of immune hepatitis may be potentially susceptible to the anti-inflammatory properties of PPAR $\gamma$. Moreover, it has been reported that reduced liver injury after flavonoid treatment in the model of GalN/LPS hepatitis was associated with increased expression of PPAR $\gamma$ [12]. This prompted us to investigate whether pharmacological activation of PPAR $\gamma$ can augment the anti-inflammatory function of different hepatic immune cells and whether this influences liver injury in the murine model of immune-mediated GalN/LPS-induced hepatitis.

\section{Results}

\subsection{PPAR $\gamma$ Activation Regulates Pro-Inflammatory Activity in liver sinusoidal endothelial cells (LSEC) and $T$} Cells but not Kupffer Cells

PPAR $\gamma$ has been shown to have anti-inflammatory effects on different cells of the immune system. We have previously observed that PPAR $\gamma$ activation in DC leads to a diminished production of pro-inflammatory cytokines after TLR stimulation [6]. PPAR $\gamma$ activation in peritoneal macrophages also inhibits their immune function, resulting in reduced respiratory burst and TNF $\alpha$ production [2].

In murine models of immune-mediated hepatitis, immune cells involved in the induction of liver damage include LSEC, CD4 T cells and Kupffer cells [13-15]. Thus, we investigated the effect of in vivo PPAR $\gamma$ activation on these immune cell populations. Mice were fed with the PPAR $\gamma$ ligand Pioglitazone (Pio) or the vehicle carboxy-methyl-cellulose ( $\mathrm{cmc}$ ) alone for 7 days, after which LSEC or Kupffer cells were isolated from the liver, or T lymphocytes from the spleen. As LSEC express TLR4 [16], we stimulated LSEC isolated from Pio- and vehicle-fed mice with the TLR4 ligand LPS and analyzed their production of the pro-inflammatory cytokine IL-6. LPS induced substantial IL-6 production by LSEC, which was significantly reduced when PPAR $\gamma$ was activated (Figure 1A). Similarly, PPAR $\gamma$ activation in vivo inhibited the function of splenic T cells as their ability to produce IFN $\gamma$ (Figure 1B)

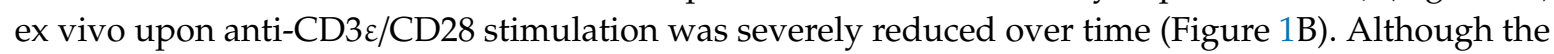
anti-inflammatory effects of PPAR $\gamma$ in macrophages have been well documented [2], in vivo PPAR $\gamma$ activation did not inhibit TNF $\alpha$ production by Kupffer cells ex vivo after LPS stimulation (Figure 1C), but increased early $(24 \mathrm{~h}$ ) but not late $(48 \mathrm{~h}) \mathrm{TNF} \alpha$ production. Taken together, our data suggest that in vivo PPAR $\gamma$ ligation has potent anti-inflammatory effects on T cells and LSEC, but not on TNF $\alpha$ production by Kupffer cells. 

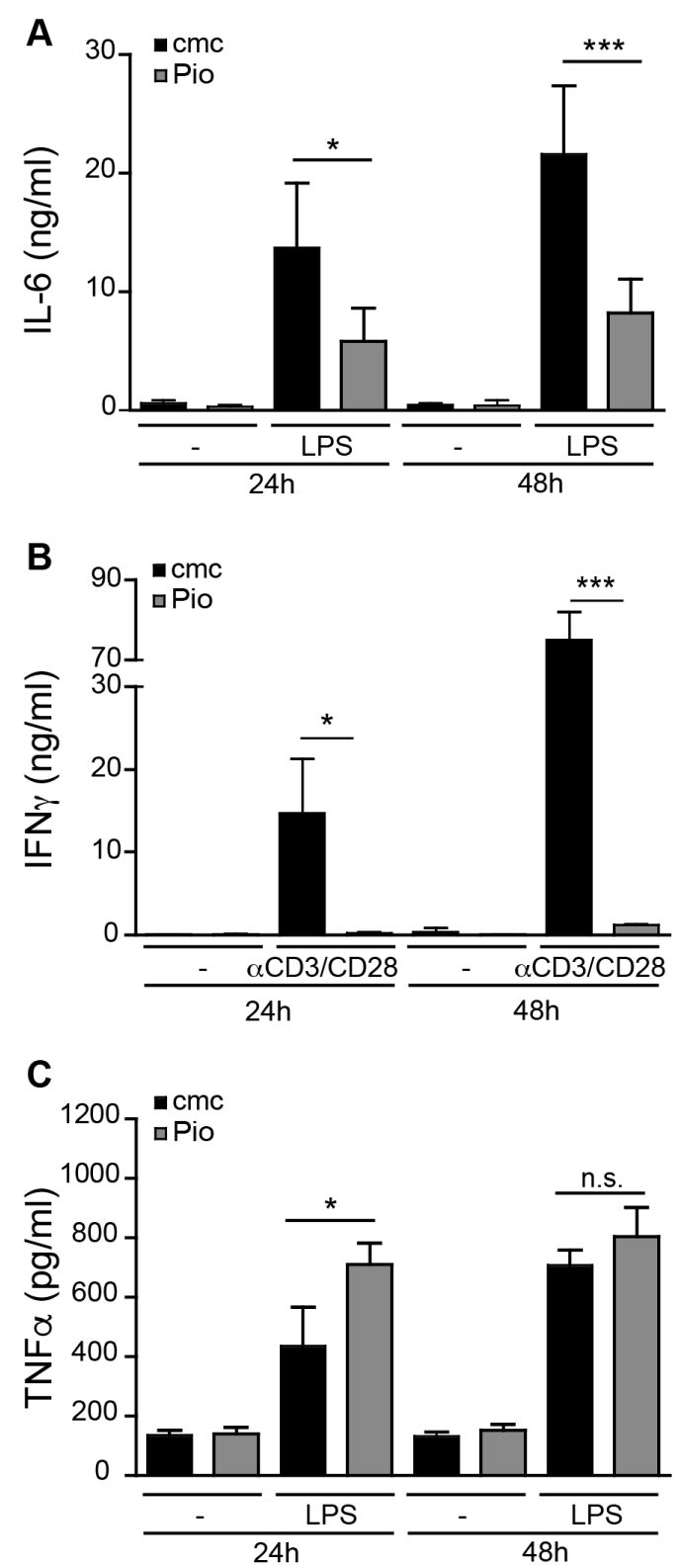

Figure 1. In vivo PPAR $\gamma$ activation reduces pro-inflammatory activity in LSEC and splenic T cells but not Kupffer cells ex vivo. C57BL/6 mice were fed for 7 days with $30 \mathrm{mg} / \mathrm{kg}$ Pioglitazone (Pio) or with vehicle $(\mathrm{cmc})$ alone. (A) LSEC were isolated from the livers of these mice and stimulated in vitro with $100 \mathrm{ng} / \mathrm{mL}$ of the TLR4 ligand LPS or were left untreated. After 24 and $48 \mathrm{~h}$, IL-6 content in the supernatant was determined by ELISA. (B) CD8 T cells were isolated from the spleen and stimulated

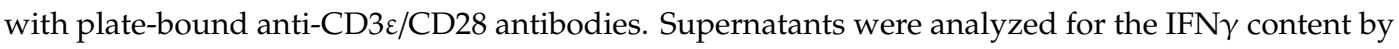
ELISA after 24 and $48 \mathrm{~h}$. (C) Kupffer cells were isolated from Pio-treated and non-treated mice and incubated with $100 \mathrm{ng} / \mathrm{mL}$ LPS. TNF $\alpha$ content in the supernatant was measured after 24 and $48 \mathrm{~h}$ by ELISA. Data are presented as mean \pm Standard Deviation (SD); one representative experiment out of three is shown. ${ }^{*} p \leq 0.05,{ }^{* * *} p \leq 0.001$, n.s. $=$ not significant.

\subsection{PPAR $\gamma$ Activation in LSEC Does Not Influence T Cell Modulatory Capacity}

Although LSEC can produce pro-inflammatory cytokines, like IL-6, under homeostasis, LSEC display immune modulatory functions towards T lymphocytes [17]. Cross-presentation of systemic antigens by LSEC results in the induction of CD8 T cells lacking an immediate effector function, but possessing a memory function [18]. As we found that PPAR $\gamma$ activation influences LSEC function with respect to LPS-induced IL-6 production (Figure 1A), and as we have previously shown that $\mathrm{T}$ cell 
stimulatory function in dendritic cells is severely affected after PPAR $\gamma$ ligation $[6,19]$, we analyzed the ability of PPAR $\gamma$-activated LSEC to fulfill their function as regulatory antigen-presenting cells. First, we examined initial CD8 T cell stimulation by LSEC and compared it to splenic DC isolated from Pio- or vehicle-fed mice. Early IL-2 and IFN $\gamma$ production by CD8 $\mathrm{T}$ cells was not affected by PPAR $\gamma$ ligation in antigen-presenting DC (Figure 2A). In contrast, IL-2 and IFN $\gamma$ production in CD8 T cells activated by PPAR $\gamma$-activated LSEC was increased after $24 \mathrm{~h}$ (Figure 2A). This difference was not reflected in the induction of proliferation in CD8 T cells, as both PPAR $\gamma$-activated DC and LSEC induced a delay in T cell proliferation (Figure 2B). However, after re-stimulation of LSEC-primed or DC-primed CD8 T cells, PPAR $\gamma$ activation in DC reduced IFN $\gamma$ production in DC-primed CD8 T cells, similar to what we found previously for CD4 T cell priming [6], but LSEC-primed T cells failed to produce IFN $\gamma$ upon re-stimulation, irrespective of PPAR $\gamma$ activation (Figure 2C). In summary, these data show that although PPAR $\gamma$ activation in LSEC affects pro-inflammatory cytokine production, it does not alter their function with respect to CD8 T cell priming.
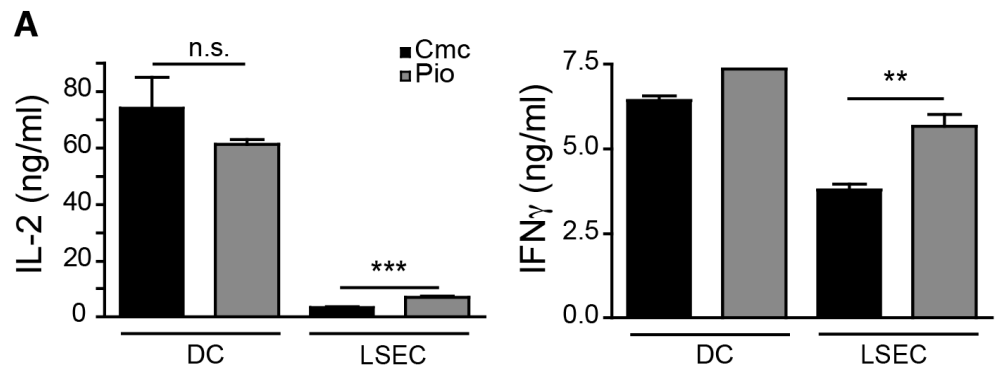

B

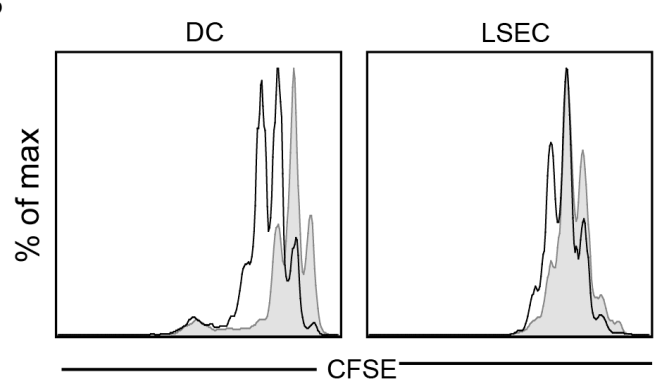

C

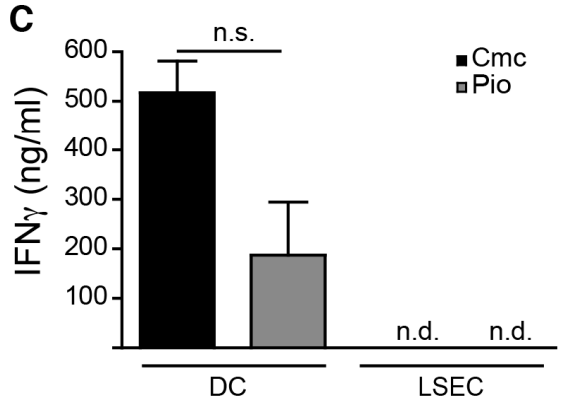

Figure 2. PPAR $\gamma$ activation does not alter T cell function after priming by LSEC. C57BL/6 mice were fed for 7 days with $30 \mathrm{mg} / \mathrm{kg}$ Pioglitazone or with vehicle ( $\mathrm{cmc}$ ) alone. LSEC and dendritic cells (DC) were isolated from these mice and cocultured with purified ovalbumin (OVA)-specific CFSE-labeled OT-1 CD8 T cells in the presence of $100 \mu \mathrm{g} / \mathrm{mL}$ OVA. (A) After $24 \mathrm{~h}$, IL-2 and IFN $\gamma$ release was determined by ELISA. (B) After $72 \mathrm{~h}$, the proliferation profile of the OT-1 CD8 T cells was determined by flow cytometry (black line, no fill $=\mathrm{cmc}$, grey line, grey fill $=$ Pio). $(\mathbf{C})$ After 4 days of coculture, CD8 T cells were re-stimulated with plate-bound anti-CD3ع/CD28 antibodies and $24 \mathrm{~h}$ later, production of IFN $\gamma$ was measured by ELISA. Error bars indicate mean $\pm \mathrm{SD}, n=3$; one representative experiment out of three is shown. ${ }^{* *} p \leq 0.01,{ }^{* * *} p \leq 0.001$, n.s. $=$ not significant, n.d. $=$ not detected.

\subsection{Pioglitazone-Mediated PPAR $\gamma$ Activation Aggravates GalN/LPS-Induced Hepatitis}

We next investigated if the anti-inflammatory effects of PPAR $\gamma$ acting on the various cell populations in the liver, that we observed in vitro, were sufficient to influence the course of liver inflammation in the GalN/LPS model [20] of immune-mediated hepatitis. To this end, we injected Pioglitazone- or vehicle-fed mice with GalN/LPS and measured plasma alanine aminotransferase (ALT) levels 6-7 h later. Unexpectedly, the administration of GalN/LPS to Pio-fed mice did not ameliorate but instead significantly exacerbated liver injury, as measured by plasma ALT levels (Figure 3A) and a significantly higher liver injury score in histology (Figure 3B). As we found that Kupffer cells from Pioglitazone-fed mice increased their early TNF $\alpha$ secretion in vitro (Figure 1C), we 
next investigated whether the observed increased liver injury after Pioglitazone administration in GalN/LPS administration in Pio-fed mice involves TNF $\alpha$.

A

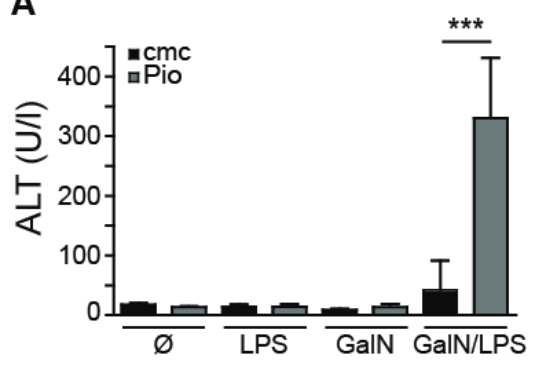

C

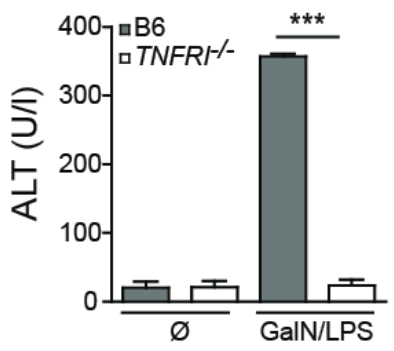

$\mathbf{F}$

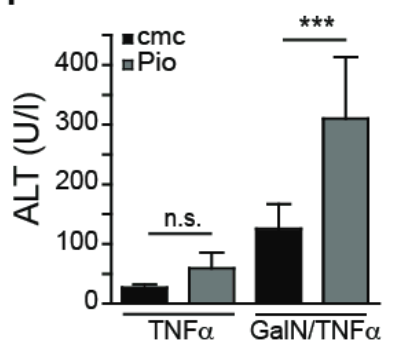

B
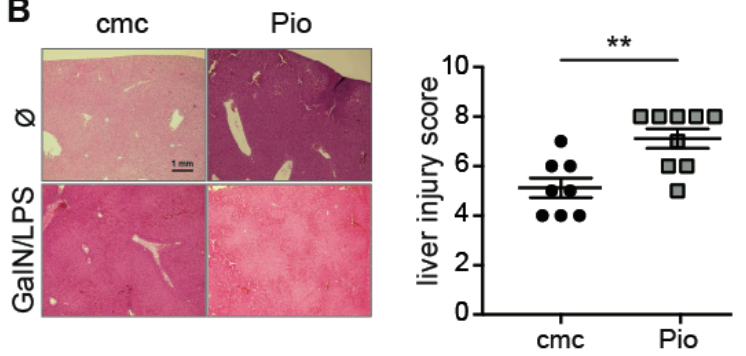

E
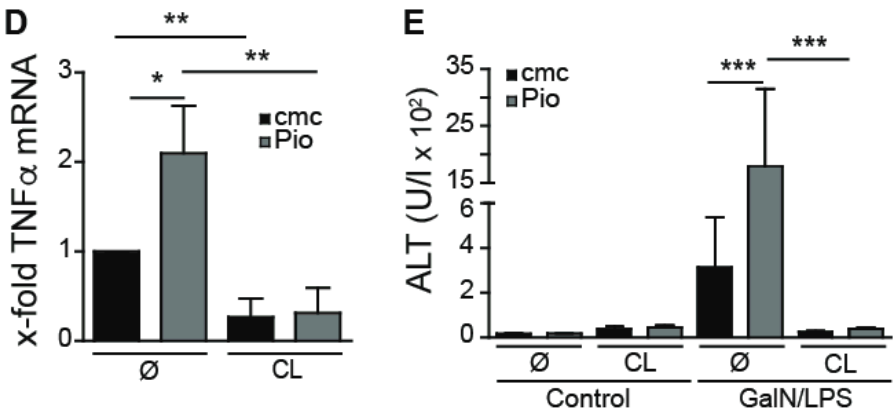

Figure 3. Oral administration of Pioglitazone sensitizes mice for immune-mediated experimental hepatitis. (A,B,D,E,F) C57BL/6 and (C) TNF receptor I (TNFRI) ${ }^{-/}$mice were fed with $30 \mathrm{mg} / \mathrm{kg}$ Pioglitazone or with vehicle (cmc) for 7 days. (A) Plasma ALT levels from C57BL/6 mice after 6-7 h after the i.p. injection of GalN, LPS, GalN/LPS or phospate buffered saline (PBS). (B) Exemplary H\&E staining of livers of as-indicated at $20 \times$ magnification. The bar graph depicts a histological liver injury score as detailed in the Materials and Method Section of vehicle $(n=7)$ and vehicle + Pioglitazone $(n=$ 9)-treated mice. (C) Plasma ALT levels 6-7 h after i.p. GalN/LPS or PBS injection into C57BL/6 and $\mathrm{TNFRI}^{-/-}$mice that were fed with Pio for 7 days. (D) C57BL/6 mice that were fed with Pio or vehicle $(\mathrm{cmc})$ for 7 days were injected with clodronate liposomes (CL) or were left untreated. Then, mice received GalN/LPS i.p. and $1 \mathrm{~h}$ later, intrahepatic TNF $\alpha$ mRNA levels were determined by real-time polymerase chain reaction (PCR). (E) Plasma ALT levels were determined 6-7 h after injection of GalN/LPS in clodronate liposome (CL)-injected and non-injected C57BL/6 mice. (F) Pio- and vehicle-fed C57BL/6 mice were injected with $400 \mathrm{ng}$ TNF $\alpha 30$ min post GalN injection or received GalN alone. Plasma ALT levels were measured $4 \mathrm{~h}$ later. Error bars indicate mean $\pm \mathrm{SD}, n \geq 4$; one representative experiment (A, C-F) out of three is shown. ${ }^{*} p \leq 0.05,{ }^{* *} p \leq 0.01,{ }^{* * *} p \leq 0.001$, n.s. $=$ not significant.

We first established that after GalN/LPS injection, the production of TNF $\alpha$ was essential for the ensuing liver injury, as GalN/LPS injection in TNFRI-deficient mice, unable to respond to TNF $\alpha$, did not induce any liver injury, as measured by plasma ALT levels (Figure 3C). We could further show that in Pio-fed mice that were challenged with GalN/LPS, intrahepatic TNF $\alpha$ mRNA levels were increased (Figure 3D). Macrophages/Kupffer cells are the main producers of TNF $\alpha$ in the 
GalN/LPS model [21], and the activation of PPAR $\gamma$ by Pioglitazone in macrophages has been described to diminish TNF $\alpha$ production by these cells [1]. However, our results demonstrated that in vivo Pioglitazone administration does not reduce LPS-induced TNF $\alpha$ production by Kupffer cells (Figure 1C). To investigate whether Kupffer cells were responsible for the increased intrahepatic TNF $\alpha$ mRNA levels after GalN/LPS injection in Pio-fed animals, we depleted Kupffer cells by the administration of clodronate liposomes (CL) to Pio- or vehicle-fed mice before administration of GalN/LPS (Figure 3D). In the absence of Kupffer cells, we did not detect elevated TNF $\alpha$ mRNA levels in Pio-fed compared to control-fed mice (Figure 3D). Moreover, in CL-treated animals, we did not observe any increase in TNF $\alpha$ mRNA levels (Figure 3D), nor did these mice develop hepatitis with increased plasma ALT levels (Figure 3E), indicating that Kupffer cells producing increased levels of TNF $\alpha$ were the primary cause of augmented liver damage after GalN/LPS in Pio-fed mice. Interestingly, we could previously show in a model of hepatic adenovirus infection, that hepatocytes can develop an increased sensitivity towards $\mathrm{TNF} \alpha$-mediated signaling after infection [22]. To test whether hepatocytes show such heightened sensitivity, we administered a set concentration of recombinant TNF $\alpha$, instead of LPS, to GalN-treated mice. When receiving the same amount of TNF $\alpha$ in combination with GalN, the Pio-fed mice had higher plasma ALT levels (Figure 3F), indicating that Pioglitazone administration not only induces higher levels of TNF $\alpha$ but at the same time, increases the sensitivity of GalN-treated hepatocytes towards the produced TNF $\alpha$. Interestingly, even in the absence of GalN administration, the injection of TNF $\alpha$ resulted in a slight increase in plasma ALT in Pio-fed mice compared to vehicle-fed mice, suggesting that Pioglitazone by itself is capable to sensitize hepatocyte towards the death-inducing effect of TNF $\alpha$. Taken together, our data suggest that the administration of Pioglitazone worsens the outcome of immune-mediated hepatitis by a combination of unexpected induction of higher levels of $\mathrm{TNF} \alpha$ in Kupffer cells and an additional sensitization of hepatocytes towards TNF $\alpha$-induced death.

\section{Discussion}

Activation of the anti-inflammatory transcription factor PPAR $\gamma$ is known to reduce production of inflammatory mediators in macrophages and dendritic cells $[6,23]$. Furthermore, PPAR $\gamma$ activation has been described to downregulate inflammatory responses [10,24] and can either directly [9] or indirectly affect $\mathrm{T}$ cell immunity [6]. Also, in our experiments, PPAR $\gamma$ activation had strong immunomodulatory effects in T cells and almost completely inhibited effector cytokine production following activation through the T cell receptor. We additionally found that PPAR $\gamma$ activation in liver-resident LSEC reduced the production of pro-inflammatory cytokines like IL- 6 after LPS stimulation but did not significantly influence their function with regards to CD8 T cell priming. Although PPAR $\gamma$ activation in macrophages has been reported to result in marked inhibition of TNF $\alpha$ production [1], it did not decrease in the case of liver-resident Kupffer cells, but temporarily increased TNF $\alpha$ production upon TLR stimulation after PPAR $\gamma$ activation. Together, these results demonstrate that the consequences of pharmacologic PPAR $\gamma$ activation vary between different immune cells or even between macrophages from different organs, and that liver macrophages are non-responsive towards the anti-inflammatory effects of pharmacologic PPAR $\gamma$ activation.

To study the in vivo effects of PPAR $\gamma$ activation in immune-mediated hepatitis, in which the interplay between immune and non-immune cells is pivotal for liver injury, we analyzed the effect of pharmacologic PPAR $\gamma$ activation in the experimental hepatitis model based on the application of Galactosamine and LPS. Most strikingly, we found that PPAR $\gamma$ activation by Pioglitazone administration did not reduce but rather exacerbated GalN/LPS hepatitis. These findings in GalN/LPS hepatitis were unexpected as it has been reported that increased hepatic PPAR $\gamma$ expression during GalN/LPS hepatitis was associated with decreased severity [12], and we observed that isolated immune cell populations, such as LSEC and T cells, responded to pharmacologic PPAR $\gamma$ activation with reduced pro-inflammatory cytokine production. Although dendritic cells and macrophages have been shown to secrete less inflammatory cytokines after Pioglitazone-mediated PPAR $\gamma$ activation $[2,6]$, our experiments indicate that the effect of Pioglitazone administration on single isolated hepatic immune cell populations cannot 
predict the influence of pharmacologic PPAR $\gamma$ activation in vivo in an experimental model of hepatitis. Critical to the pathogenesis of liver damage in GalN/LPS-induced hepatitis is the expression of TNF $\alpha$. As we could show that following application of Pioglitazone, TNF $\alpha$ gene expression is increased in GalN/LPS-treated mice, it is possible that this leads to the observed increase in ALT levels in the plasma of these mice. The elevated TNF $\alpha$ levels upon GalN/LPS injection in Pioglitazone-treated animals may be attributed to the increased production of TNF $\alpha$ by hepatic macrophages. Indeed, ex vivo TLR-stimulated Kupffer cells from Pioglitazone-fed mice showed a tendency to produce more TNF $\alpha$ in vitro. Under non-inflammatory conditions, the liver is constantly exposed to low levels of LPS coming from the gastrointestinal tract, leading to a reduced sensitivity of hepatic antigen-presenting cells to subsequent LPS-mediated stimulation [25,26], which is called LPS/endotoxin tolerance [27]. The induction of such LPS tolerance is dependent on TLR4 signaling resulting in an initial NF- $\mathrm{KB}$ activation [27], after which a reduced sensitivity to further pro-inflammatory stimuli is established. The activation of PPAR $\gamma$ by Pioglitazone, which inhibits NF-kB-mediated transcription [2], may prevent the induction of such endotoxin tolerance by inhibiting the initial TLR-dependent NF- $\mathrm{KB}$ activation and thus resulting in an increased TNF $\alpha$ production by macrophages in Pioglitazone-fed mice that are challenged with LPS. Exacerbating the effects of overproduction of TNF $\alpha$ by liver macrophages in this system could be the reciprocal decrease in anti-inflammatory IL-10 production by macrophages [28], that has been reported to be able to significantly reduce or even prevent GalN/LPS-induced liver injury [29]. Conversely, inhibiting PPAR $\gamma$ via antagonist administration could reverse this situation, possibly leading to a protective effect in GalN/LPS-induced liver injury.

The family of thiazolidinediones is widely used to activate PPAR $\gamma$ in the treatment of type II diabetes. Interestingly, Troglitazone, like Pioglitazone, a member of the thiazolidinediones, can cause PPAR $\gamma$-independent hepatotoxicity, potentially leading to hepatic organ failure [30,31]. It is thought that during metabolization of Troglitazone in the liver, chemically reactive metabolites may be formed, potentially leading to hepatocyte apoptosis and hepatotoxicity [32,33]. Although Pioglitazone administration is not associated with lethal liver injury in patients, Pioglitazone administration, similar to Troglitazone, leads to elevated plasma ALT levels in patients [34], indicating that Pioglitazone may cause minimal damage to the liver. Our results indicate that Pioglitazone administration leads to an increase in liver damage after GalN/LPS administration due to elevated TNF $\alpha$ production by liver-resident macrophages. Additionally, our data suggest that Pioglitazone increases the susceptibility of hepatocytes to the death-inducing effects of TNF $\alpha$. Indeed, some case reports suggest that in human patients, receiving Pioglitazone as a treatment, for instance, for Type II diabetes, a similar course of events may be possible, leading to acute liver damage with high ALT, which is reversed as soon as Pioglitazone treatment is discontinued $[35,36]$. However, such increased sensitivity of hepatocytes towards TNF $\alpha$ may not be restricted to drug-induced stress in hepatocytes, but may also occur when hepatocytes are virally infected, which also leads to higher liver damage upon injection of TNF $\alpha$ [22].

Although the activation of PPAR $\gamma$ by synthetic ligands has been widely accepted to have anti-inflammatory effects and even provide protection in experimental models of inflammation in the central nervous system (CNS) and the bowel, we provided evidence here that in the liver, the pharmacological activation of PPAR $\gamma$ by Pioglitazone does not protect from immune-mediated damage but instead has detrimental effects on the disease course. While our observations indicate that Pioglitazone exacerbates immune-mediated injury and thereby provides an interesting in vivo model for further research on drug-induced liver injury, the molecular and cellular mechanisms causing this augmented liver injury will require further investigation.

\section{Materials and Methods}

\subsection{Mice}

C57BL/6, H2-K $\mathrm{K}^{\mathrm{b}-S I I N F E K L}$-restricted OT-I T Cell Receptor-transgenic and TNFRI ${ }^{-/-}$mice were bred in the central animal facility in Bonn under specific pathogen-free conditions according to the Federation 
of European Laboratory Animal Science Association (FELASA) and were used for experiments at 6 to 10 weeks of age. The protocols for animal experiments were approved by the local government of North-Rhine Westphalia and the Behörde für Gesundheit und Verbraucherschutz of the Freie und Hansestadt Hamburg (permit number 8.87-50.10.37.09.137 and N002/18). All efforts were made to minimize suffering.

\subsection{Reagents}

Pioglitazone (Actos; Takeda Pharmaceuticals, Berlin, Germany) treatment of mice was performed by daily oral gavage of $30 \mathrm{mg} / \mathrm{kg}$ body weight suspended in $0.5 \%$ carboxymethylcellulose ( $\mathrm{cmc}$, Sigma-Aldrich, Munich, Germany), or vehicle only 7 days before cell isolation or induction of experimental hepatitis in vivo. For in vitro cell culture, $10 \mu \mathrm{M}$ Pioglitazone (Pio) was added into the medium daily. LSEC and Kupffer cells were stimulated with $100 \mathrm{ng} / \mathrm{mL}$ LPS (Sigma-Aldrich, Munich, Germany).

\subsection{Cell Isolation}

LSEC were isolated as described previously [36] and purified by immunogenic separation using $\alpha \mathrm{CD} 146$-microbeads (Miltenyi Biotec, Bergisch Gladbach, Germany), achieving purity of $>98 \%$ and plated into collagen-coated 24-well or 96-well plates. One day after isolation, cells were washed with PBS containing 1\% Fetal Calf Serum (FCS) and used two days later for experiments. Kupffer cells were isolated after perfusion of the liver with a collagenase solution and subsequent digestion with collagenase in vitro. After a 50\%/25\% Percoll gradient (GE Health Care, Freiburg, Germany), cells were plated, incubated at $37^{\circ} \mathrm{C}$ and washed after $30 \mathrm{~min}$. Adhering Kupffer cells were then used for experiments. After LPS stimulation of LSEC and Kupffer cells, supernatants were harvested at 24 and $48 \mathrm{~h}$ and IL-6 content was measured by ELISA. Dendritic cells (DC) were purified by immunogenic separation using $\alpha$ CD11c-microbeads (Miltenyi Biotec, Bergisch Gladbach, Germany) after collagenase-digestion of spleens according to the manufacturer's instructions. CD8+ T cells were isolated from spleens and lymph nodes of $\mathrm{H} 2-\mathrm{Kb}$-SIINFEKL-restricted OT-I TCR-transgenic mice by $\alpha \mathrm{CD} 8$-microbeads (Miltenyi Biotec).

\subsection{T Cell Assays}

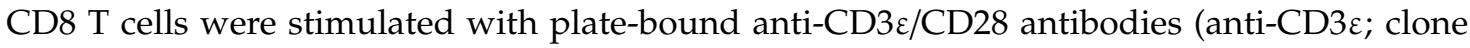
145.C11, anti-CD28; clone 37.51) in a 96-well plate. After 24 and $48 \mathrm{~h}$, supernatants were analyzed for IFN $\gamma$ content by ELISA. Carboxyfluorescein Succinimidyl Ester (CFSE)-labeled naïve OT-1 CD8+ T cells were cocultured with LSEC or DC from Pio- and vehicle-fed mice in the presence of $100 \mu \mathrm{g} / \mathrm{mL}$ OVA. After $24 \mathrm{~h}$, the IFN $\gamma$ and IL-2 content was determined in the supernatant via ELISA. Additionally, after $72 \mathrm{~h}, \mathrm{~T}$ cell proliferation was determined by flow cytometry. Acquisition and analysis were conducted using a FACS Canto II (BD, Heidelberg, Germany) and FlowJo software (TreeStar Inc., Ashland, OR, USA). After 4 days of coculture, viable CD8 T cells were isolated via density gradient centrifugation (Lonza, Cologne, Germany), re-stimulated on anti-CD3e-coated plates and supernatants were analyzed for IFN $\gamma$ content by ELISA $24 \mathrm{~h}$ later.

\subsection{Experimental Hepatitis (GalN/LPS, GalN/TNF $\alpha$ )}

All reagents were dissolved in pyrogen-free saline. GalN/LPS-mediated liver injury was induced by simultaneous i.p. injection of $20 \mathrm{mg}$ GalN (Sigma-Aldrich, Munich, Germany) and $10 \mathrm{ng}$ LPS (Sigma-Aldrich, Munich, Germany). In the GalN/TNF $\alpha$ model, 400 ng murine recombinant TNF $\alpha$ (Invitrogen, Karlsruhe, Germany) was injected i.v. after i.p. GalN injection. Plasma ALT levels were measured using the scil Reflovet ${ }^{\circledR}$ Plus analyzer (Roche, Penzberg, Germany) at the indicated times. Liver tissue was isolated for histology, RNA isolation, cDNA synthesis and quantitative PCR at the indicated times. Quantification of intrahepatic cytokine mRNA levels was performed by qPCR as described previously [37]. 


\subsection{Histology}

Liver tissue was formalin-fixed and then processed for routine paraffin embedding. Standard protocols for Hematoxylin and Eosin (H\&E) staining were used. A pathologist scored sections blindly. The liver injury score summarizes the score for plasma and lymphocytic infiltrate (0-3), granulocytic infiltrate (0-3), erythrocyte extravasation (0-3) and area of acute liver damage $(0 \%=0,0 \%-30 \%=1$, $31 \%-60 \%=2,61 \%-100 \%=3)$.

\subsection{Depletion of Macrophages by Clodronate Liposomes}

Mice were injected intravenously with liposome encapsulated dichloro- methylene- bisphosphonate $\left(\mathrm{Cl}_{2} \mathrm{MBP}\right)[38] 3$ and 1 day before inducing hepatitis.

\subsection{Statistical Analysis}

Student's $t$ or analysis of variance (ANOVA) tests were used to determine statistical significance of the results. Data are depicted as the mean \pm standard deviation (SD), and $p$-values $<0.05$ were considered significant $\left({ }^{*} p<0.05,{ }^{* *} p<0.01,{ }^{* *} p<0.001\right)$.

Author Contributions: Conceptualization, L.K., P.A.K. and L.D.; Data curation, R.S., C.M. and A.E.; Formal analysis, R.S.; Funding acquisition, P.A.K. and L.D.; Investigation, L.U., B.G. and L.C.H.; Methodology, L.C.H.; Resources, D.W., G.T., N.v.R. and L.K.; Supervision, P.A.K. and L.D.; Writing-original draft, R.S., P.A.K. and L.D.; Writing-review and editing, G.T. and L.D. All authors have read and agreed to the published version of the manuscript.

Funding: L.D. and P.K. were supported by the Deutsche Forschungsgemeinschaft SFB704 project A5 and L.D. and G.T. were supported by the Deutsche Forschungsgemeinschaft SFB841 projects B09 (L.D.) and B01 (G.T.)

Acknowledgments: We would like to thank the technical assistance of A. Dolf and E. Endl of the Flow Cytometry core facility of the University Hospital, Bonn.

Conflicts of Interest: The authors declare no conflict of interest.

\section{References}

1. Jiang, C.; Ting, A.T.; Seed, B. PPAR-gamma agonists inhibit production of monocyte inflammatory cytokines. Nature 1998, 391, 82-86. [CrossRef] [PubMed]

2. Ricote, M.; Li, A.C.; Willson, T.M.; Kelly, C.J.; Glass, C.K. The peroxisome proliferator-activated receptor-gamma is a negative regulator of macrophage activation. Nature 1998, 391, 79-82. [CrossRef] [PubMed]

3. Kaplan, J.; Nowell, M.; Chima, R.; Zingarelli, B. Pioglitazone reduces inflammation through inhibition of NF-kB in polymicrobial sepsis. Innate Immun. 2014, 20, 519-528. [CrossRef] [PubMed]

4. Széles, L.; Töröcsik, D.; Nagy, L. PPARgamma in immunity and inflammation: Cell types and diseases. Biochim. Biophys. Acta 2007, 1771, 1014-1030. [CrossRef] [PubMed]

5. Rizos, C.V.; Kei, A.; Elisaf, M.S. The current role of thiazolidinediones in diabetes management. Arch. Toxicol. 2016, 90, 1861-1881. [CrossRef] [PubMed]

6. Klotz, L.; Dani, I.; Edenhofer, F.; Nolden, L.; Evert, B.; Paul, B.; Kolanus, W.; Klockgether, T.; Knolle, P.; Diehl, L. Peroxisome proliferator-activated receptor gamma control of dendritic cell function contributes to development of CD4+ T cell anergy. J. Immunol. 2007, 178, 2122-2131. [CrossRef] [PubMed]

7. Zhu, W.; Yan, H.; Li, S.; Nie, W.; Fan, F.; Zhu, J. PPAR- $\gamma$ agonist pioglitazone regulates dendritic cells immunogenicity mediated by DC-SIGN via the MAPK and NF-кB pathways. Int Immunopharmacol. 2016, 41, 24-34. [CrossRef]

8. Rigamonti, E.; Chinetti-Gbaguidi, G.; Staels, B. Regulation of macrophage functions by PPAR-alpha, PPAR-gamma, and LXRs in mice and men. Arterioscler. Thromb. Vasc. Biol. 2008, 28, 1050-1059. [CrossRef]

9. Klotz, L.; Burgdorf, S.; Dani, I.; Saijo, K.; Flossdorf, J.; Hucke, S.; Alferink, J.; Novak, N.; Beyer, M.; Mayer, G.; et al. The nuclear receptor PPAR gamma selectively inhibits Th17 differentiation in a T cell-intrinsic fashion and suppresses CNS autoimmunity. J. Exp. Med. 2009, 206, 2079-2089. [CrossRef] 
10. Guri, A.J.; Mohapatra, S.K.; Horne, W.T.; Hontecillas, R.; Bassaganya-Riera, J. The role of T cell PPAR gamma in mice with experimental inflammatory bowel disease. BMC Gastroenterol. 2010, 10, 60. [CrossRef]

11. Dahten, A.; Koch, C.; Ernst, D.; Schnöller, C.; Hartmann, S.; Worm, M. Systemic PPARgamma ligation inhibits allergic immune response in the skin. J. Investig. Dermatol. 2008, 128, 2211-2218. [CrossRef]

12. Zhou, R.-J.; Ye, H.; Wang, F.; Wang, J.-L.; Xie, M.-L. Apigenin inhibits d-galactosamine/LPS-induced liver injury through upregulation of hepatic Nrf-2 and PPAR $\gamma$ expressions in mice. Biochem Biophys Res Comm. 2017, 493, 625-630. [CrossRef] [PubMed]

13. Knolle, P.A.; Gerken, G.; Loser, E.; Dienes, H.P.; Gantner, F.; Tiegs, G.; Meyer zum Buschenfelde, K.H.; Lohse, A.W. Role of sinusoidal endothelial cells of the liver in concanavalin A-induced hepatic injury in mice. Hepatology 1996, 24, 824-829. [CrossRef] [PubMed]

14. Tiegs, G.; Hentschel, J.; Wendel, A. A T cell-dependent experimental liver injury in mice inducible by concanavalin A. J. Clin. Investig. 1992, 90, 196-203. [CrossRef] [PubMed]

15. Schumann, J.; Wolf, D.; Pahl, A.; Brune, K.; Papadopoulos, T.; van Rooijen, N.; Tiegs, G. Importance of Kupffer cells for T-cell-dependent liver injury in mice. Am. J. Pathol. 2000, 157, 1671-1683. [CrossRef]

16. Kern, M.; Popov, A.; Scholz, K.; Schumak, B.; Djandji, D.; Limmer, A.; Eggle, D.; Sacher, T.; Zawatzky, R.; Holtappels, R.; et al. Virally infected mouse liver endothelial cells trigger CD8+ T-cell immunity. Gastroenterology 2010, 138, 336-346. [CrossRef]

17. Diehl, L.; Schurich, A.; Grochtmann, R.; Hegenbarth, S.; Chen, L.; Knolle, P.A. Tolerogenic maturation of liver sinusoidal endothelial cells promotes B7-homolog 1-dependent CD8+ T cell tolerance. Hepatology 2008, 47, 296-305. [CrossRef]

18. Böttcher, J.P.; Schanz, O.; Wohlleber, D.; Abdullah, Z.; Debey-Pascher, S.; Staratschek-Jox, A.; Höchst, B.; Hegenbarth, S.; Grell, J.; Limmer, A.; et al. Liver-primed memory T cells generated under noninflammatory conditions provide anti-infectious immunity. Cell Rep. 2013, 3, 779-795. [CrossRef]

19. Klotz, L.; Hucke, S.; Thimm, D.; Classen, S.; Gaarz, A.; Schultze, J.; Edenhofer, F.; Kurts, C.; Klockgether, T.; Limmer, A.; et al. Increased antigen cross-presentation but impaired cross-priming after activation of peroxisome proliferator-activated receptor gamma is mediated by up-regulation of B7H1. J. Immunol. 2009, 183, 129-136. [CrossRef]

20. Galanos, C.; Freudenberg, M.A.; Reutter, W. Galactosamine-induced sensitization to the lethal effects of endotoxin. Proc. Natl. Acad. Sci. USA 1979, 76, 5939-5943. [CrossRef]

21. Freudenberg, M.A.; Galanos, C. Tumor necrosis factor alpha mediates lethal activity of killed gram-negative and gram-positive bacteria in D-galactosamine-treated mice. Infect. Immun. 1991, 59, 2110-2115. [CrossRef] [PubMed]

22. Wohlleber, D.; Kashkar, H.; Gärtner, K.; Frings, M.K.; Odenthal, M.; Hegenbarth, S.; Börner, C.; Arnold, B.; Hämmerling, G.; Nieswandt, B.; et al. TNF-induced target cell killing by CTL activated through cross-presentation. Cell Rep. 2012, 2, 478-487. [CrossRef] [PubMed]

23. Uchimura, K.; Nakamuta, M.; Enjoji, M.; Irie, T.; Sugimoto, R.; Muta, T.; Iwamoto, H.; Nawata, H. Activation of retinoic $\mathrm{X}$ receptor and peroxisome proliferator-activated receptor-gamma inhibits nitric oxide and tumor necrosis factor-alpha production in rat Kupffer cells. Hepatology 2001, 33, 91-99. [CrossRef] [PubMed]

24. Feinstein, D.L.; Galea, E.; Gavrilyuk, V.; Brosnan, C.F.; Whitacre, C.C.; Dumitrescu-Ozimek, L.; Landreth, G.E.; Pershadsingh, H.A.; Weinberg, G.; Heneka, M.T. Peroxisome proliferator-activated receptor-gamma agonists prevent experimental autoimmune encephalomyelitis. Ann. Neurol. 2002, 51, 694-702. [CrossRef] [PubMed]

25. Knolle, P.A.; Loser, E.; Protzer, U.; Duchmann, R.; Schmitt, E.; zum Büschenfelde, K.H.; Rose-John, S.; Gerken, G. Regulation of endotoxin-induced IL-6 production in liver sinusoidal endothelial cells and Kupffer cells by IL-10. Clin. Exp. Immunol. 1997, 107, 555-561. [CrossRef] [PubMed]

26. Freudenberg, M.A.; Galanos, C. Induction of tolerance to lipopolysaccharide (LPS)-D-galactosamine lethality by pretreatment with LPS is mediated by macrophages. Infect Immun. 1988, 56, 1352-1357. [CrossRef] [PubMed]

27. Biswas, S.K.; Lopez-Collazo, E. Endotoxin tolerance: New mechanisms, molecules and clinical significance. Trends Immunol. 2009, 30, 475-487. [CrossRef]

28. Heming, M.; Gran, S.; Jauch, S.L.; Fischer-Riepe, L.; Russo, A.; Klotz, L.; Hermann, S.; Schäfers, M.; Roth, J.; Barczyk-Kahlert, K. Peroxisome Proliferator-Activated Receptor- $\gamma$ Modulates the Response of Macrophages to Lipopolysaccharide and Glucocorticoids. Front. Immunol. 2018, 9, 803-816. [CrossRef] 
29. Santucci, L.; Fiorucci, S.; Chiorean, M.; Brunori, P.M.; di Matteo, F.M.; Sidoni, A.; Mifliorati, G.; Morelli, A. Interleukin 10 reduces lethality and hepatic injury induced by lipopolysaccharide in galactosamine-sensitized mice. YGAST 1996, 111, 736-744. [CrossRef]

30. Neuschwander-Tetri, B.A.; Isley, W.L.; Oki, J.C.; Ramrakhiani, S.; Quiason, S.G.; Phillips, N.J.; Brunt, E.M. Troglitazone-induced hepatic failure leading to liver transplantation. A case report. Ann. Intern. Med. 1998, 129, 38-41. [CrossRef]

31. Watkins, P.B.; Whitcomb, R.W. Hepatic dysfunction associated with troglitazone. N. Engl. J. Med. 1998, 338, 916-917. [CrossRef] [PubMed]

32. Ikeda, T. Drug-induced idiosyncratic hepatotoxicity: Prevention strategy developed after the troglitazone case. Drug Metab. Pharmacokinet. 2011, 26, 60-70. [CrossRef] [PubMed]

33. Lu, M.; Kwan, T.; Yu, C.; Chen, F.; Freedman, B.; Schafer, J.M.; Lee, E.J.; Jameson, J.L.; Jordan, V.C.; Cryns, V.L. Peroxisome proliferator-activated receptor gamma agonists promote TRAIL-induced apoptosis by reducing survivin levels via cyclin D3 repression and cell cycle arrest. J. Biol. Chem. 2005, 280, 6742-6751. [CrossRef] [PubMed]

34. Tolman, K.G.; Chandramouli, J. Hepatotoxicity of the thiazolidinediones. Clin. Liver Dis. 2003, 7, 369-379. [CrossRef]

35. May, L.; Lefkowitsch, J.; Kram, M.; Rubin, D. Mixed hepatocellular-cholestatic liver injury after pioglitazone therapy. Ann. Intern. Med. 2002, 136, 449-452. [CrossRef]

36. Pinto, A.; Cummings, O.; Chalasani, N. Severe but reversible cholestatic liver injury after pioglitazone therapy. Ann. Intern. Med. 2002, 137, 857. [CrossRef]

37. Erhardt, A.; Biburger, M.; Papadopoulos, T.; Tiegs, G. IL-10, regulatory T cells, and Kupffer cells mediate tolerance in concanavalin A-induced liver injury in mice. Hepatology 2007, 45, 475-485. [CrossRef]

38. Van Rooijen, N.; Sanders, A. Liposome mediated depletion of macrophages: Mechanism of action, preparation of liposomes and applications. J. Immunol. Methods 1994, 174, 83-93. [CrossRef]

(C) 2020 by the authors. Licensee MDPI, Basel, Switzerland. This article is an open access article distributed under the terms and conditions of the Creative Commons Attribution (CC BY) license (http://creativecommons.org/licenses/by/4.0/). 